\title{
Neutrophil-to-Lymphocyte Ratio: A Systemic Inflammatory Index for Primary Diagnosis and Prognosis of Cholangiocarcinoma
}

\author{
Chalongchai Chalermwat ${ }^{1}$, Atit Silsirivanit ${ }^{1}$, Waraporn Saentaweesuk ${ }^{1}$, Vajarapong Bhudisawasdi ${ }^{2}$, Chawalit \\ Pairojkul $^{3}$, Samrit Khahmahpahte ${ }^{4}$, Tayata Thanong ${ }^{4}$, Yotsombat Changtrakul ${ }^{4}$, Katsarin Pintaraks ${ }^{4}$, Chaisiri \\ Wongkham $^{1}$ and Sopit Wongkham ${ }^{* 1}$
}

${ }^{1}$ Department of Biochemistry and Center for Translational Medicine, Faculty of Medicine, Khon Kaen University, Khon Kaen, Thailand

${ }^{2}$ Department of Surgery, Faculty of Medicine, Khon Kaen University, Khon Kaen, Thailand

${ }^{3}$ Department of Pathology, Faculty of Medicine, Khon Kaen University, Khon Kaen, Thailand

${ }^{4}$ Clinical Laboratory Section, Srinagarind Hospital, Faculty of Medicine, Khon Kaen University, Khon Kaen, Thailand

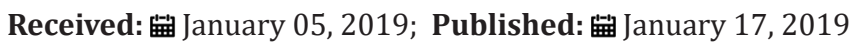

*Corresponding author: Sopit Wongkham, Department of Biochemistry, Faculty of Medicine, Khon Kaen University, Khon Kaen, 40002, Thailand

\begin{abstract}
Cholangiocarcinoma (CCA) is a major cause of cancer death in the northeastern Thailand. A primary diagnosis for CCA is essential to reduce the mortality of CCA patients. In this study, the Neutrophil-to-Lymphocyte ratio (NLR) was demonstrated for the first time to be a potential primary diagnostic index for CCA. NLR was determined in parallel with serum CA19-9, in histologically proven CCA patients ( $\mathrm{n}=103$ ) and non-CCA subjects $(\mathrm{n}=217)$. CCA patients exhibited significantly higher NLRs (mean $\pm \mathrm{SD}, 4.88 \pm 3.95)$ than the non-CCA subjects $(2.34 \pm 1.63)(P<0.001)$. NLR had diagnostic power for CCA with an area under curve (AUC) of 0.773, comparable with that of CA19-9. A cut-off NLR at 2.3 provided diagnostic values for CCA with $70.9 \%$ sensitivity, $69.1 \%$ specificity, and $69.7 \%$ accuracy. Furthermore, a high NLR (>2.3) was associated with larger tumor sizes, shorter survival of CCA patients $(\mathrm{P}=0.001)$ and was suggested to be an independent poor prognostic indicator for CCA. In conclusion, besides being an indicator of poor prognosis, NLR is as good as serum CA19-9 in discriminating CCA from non-CCA conditions. This suggested the potential of using NLR as a primary diagnostic indicator of CCA, especially in the peripheral clinics where advanced biomarkers cannot be offered.
\end{abstract}

Keywords: Bile ducts; Cancer; Liver; PMN; Systemic inflammation

\section{Introduction}

A complete blood count ( $\mathrm{CBC}$ ) is one of the most common and basic laboratory tests for medical investigation in every hospital. Although the CBC is a simple blood analysis, it provides a lot of meaningful information of possible clinical conditions of the patients. The neutrophil-to-lymphocyte ratio (NLR), calculated from the ratio of absolute numbers of peripheral blood neutrophils and lymphocytes, is a useful index reflecting systemic inflammation in several pathological conditions $[1,2]$. NLR is recently reported to be a potential prognostic marker predicting the shorter survival of patients in many types of cancer, including cholangiocarcinoma (CCA) [3-5]. CCA is a tumor of bile duct epithelium where the highest incidence has been recorded in northeastern Thailand $[6,7]$. One of the major problems of CCA is lacking a sensitive and specific diagnostic aide at an early stage. Tumor markers used in the clinical practice, such as carcinoembryonic antigen (CEA) and carbohydrate antigen (CA) 19-9, are less sensitive and able to detect CCA only when tumor is in the advanced stage. High quality imaging techniques; such as magnetic resonance imaging (MRI), computed tomography (CT), and endoscopic retrograde cholangiopancreatography (ERCP); have relatively high sensitivity and specificity but are costly and available only in the tertiary hospitals.

Definitive diagnosis of CCA is the histological examination of resected tissues or aspirated tumor cells, however, these are invasive, time-consuming, and require a specialist for the analysis. Prior to having costly and invasive analyses, it would be much more helpful in terms of economic effectiveness of CCA management, to have a primary diagnostic method that is simple and cheap to indicate a person who is suspected to have CCA. In this study, it was aimed to use NLR as a representative of a systemic inflammatory response 
that reflects the primary diagnosis for CCA. It is the first time to use the power of NLR for diagnosis of CCA. NLR was compared between CCA patients and non-CCA controls, including healthy persons (HE) and patients with benign hepato-biliary diseases (BHD) and other gastrointestinal cancers (OCA). In addition, the association of NLR

\section{Material and Methods}

\section{CCA Patients and Control Subjects}

with clinical parameters of CCA patients was analyzed to reveal the prognostic relevance of NLR. Finally, the diagnostic and prognostic values of NLR were compared with the reference serum marker, CA19-9. This study provides for the first time testing the use of NLR as an alternative index for primary diagnosis and prognosis of CCA.

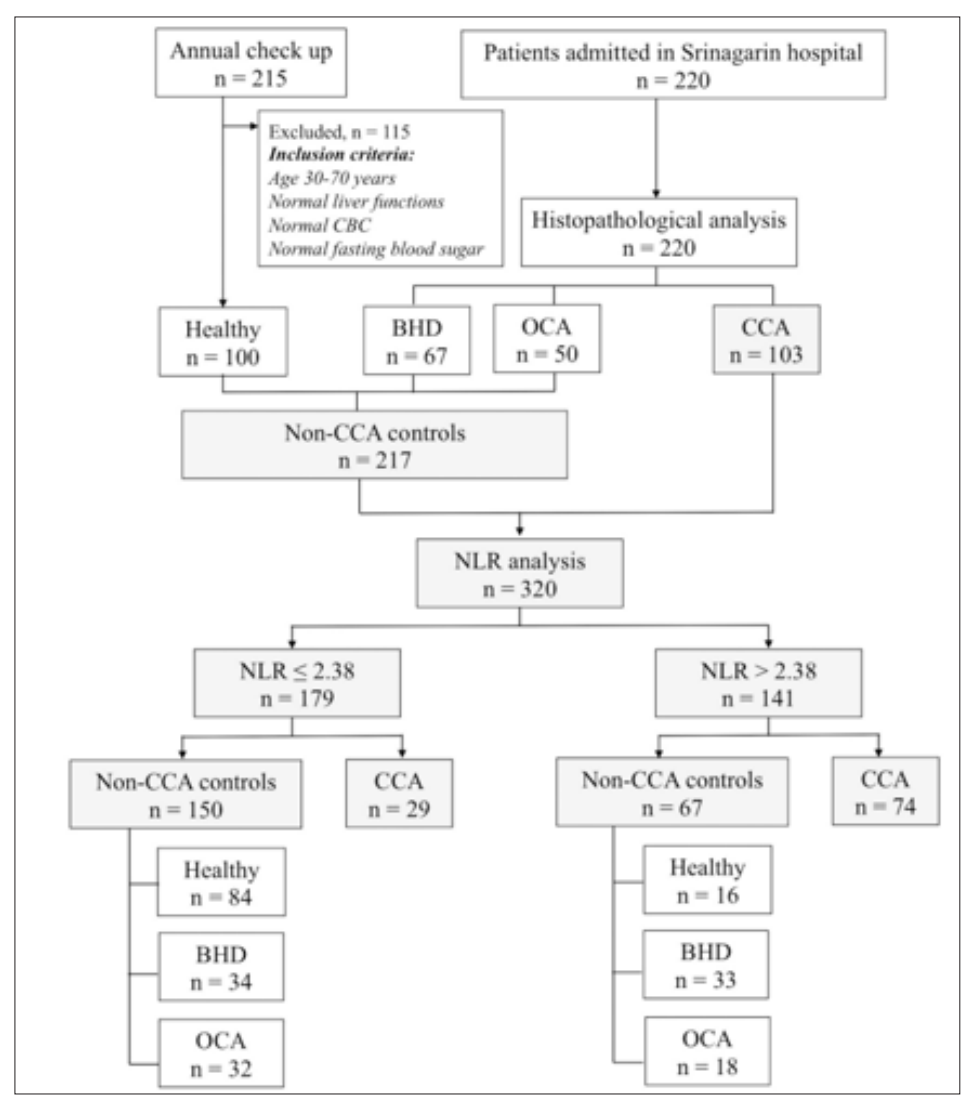

Figure 1: Patient flow diagram.

There were 320 subjects included in this study; 100 healthy individuals, and histologically proven 67 BHD, 50 OCA, and 103 CCA (Figure 1). CBCs and histological data were obtained from Department of Clinical Pathology, Srinagarind Hospital, and Department of Pathology, Faculty of Medicine, Khon Kaen University, Thailand. The study protocol was approved by the Ethics Committee for Human Research of Khon Kaen University (HE591346). Patients of BHD, OCA and CCA were admitted for surgical resection at Srinagarind Hospital, Khon Kaen University, and the final diagnoses were based on histology. The tumor stage of CCA patients was classified according to the 7th edition of the American Joint Committee on Cancer [8]. Healthy individuals were age-matched with asymptomatic persons with normal liver functions (AST $\leq 37 \mathrm{AU} / \mathrm{ml}, \mathrm{ALT} \leq 33 \mathrm{U} / \mathrm{ml}, \mathrm{ALP} \leq 121 \mathrm{U} / \mathrm{ml}$ ) and normal fasting blood glucose $(\leq 110 \mathrm{mg} / \mathrm{dl})$.

\section{Clinical Blood Parameters}

All blood parameters and clinical data were retrieved from the records of the Department of Clinical Pathology, Srinagarind
Hospital, Faculty of Medicine, Khon Kaen University, Khon Kaen, Thailand. A complete blood count was analyzed in the UnicCel ${ }^{\circledR}$ DxH-800 Coulter Cellular Analysis system (Sysmex, Japan). Liver function tests, AST, ALT, and ALP, and tumor markers, CEA, CA19-9, were measured in a Cobas-e602 automatic analyzer (Roche, Japan). Neutrophil-to-Lymphocyte Ratios (NLR) were calculated from the absolute number (cells/ $\mu$ l) of neutrophils and lymphocytes.

\section{Statistical Analysis}

Statistical analyses were performed using SPSS 16.0 (SPSS, Chicago, IL). The NLRs of each group were presented as mean \pm S.D. The differences of blood parameters between CCA and nonCCAs were compared using Student's t-test. The power of NLR to discriminate CCA vs. non-CCA was determined by the receiver operating characteristic (ROC) analysis. Chi-square $\left(\chi^{2}\right)$ was used to analyze the association of NLR and clinical outcomes of CCA patients. Survival analysis was analyzed using Kaplan-Meier plot and log-rank test. The Cox-proportional hazard model was used for multi-variate survival analysis. 


\section{Results}

\section{Patient Demographics}

There were 67 cases diagnosed as BHD ( 5 cirrhosis and hepatitis, 19 benign/pseudo tumors and high-grade biliary dysplasia, 13 bile duct dilatations and biliary hyperplasia/dysplasia, 9 cholangitis/ biliary fibrosis, 6 simple biliary cysts and heamangioma, 15 cholecystitis and cholelithiasis). OCA subjects (50 cases) were classified as hepatoma ( $\mathrm{n}=34$ ), biliary cystadenocarcinoma ( $\mathrm{n}$ $=8)$, carcinoma of ampulla of Vater and gall bladder $(n=6)$, and one each of pancreatic cancer, and 1 colon cancer. There were 103 cases identified as CCA. The age-matched HE cases $(n=100)$ were recruited from a healthy person who visited Srinagarind Hospital for annual health checkups. The demographic data of all subjects are shown in Table 1. The mean age and number of neutrophils of the subjects in each group were not significantly different. The numbers of white blood cells and neutrophils among the HE, BHD and OCA were comparable but were significantly lower than those of the CCA group $(\mathrm{P}<0.001)$.

Table 1: Demographic data.

\begin{tabular}{|c|c|c|c|c|c|c|c|c|c|}
\hline \multirow{2}{*}{ Groups } & \multicolumn{3}{|c|}{$\mathbf{n}$} & \multirow{2}{*}{$\begin{array}{c}\text { Age } \\
\text { (years) }\end{array}$} & \multirow{2}{*}{ WBC (cell/ $\mu \mathrm{l})$} & \multirow{2}{*}{$\begin{array}{l}\text { Neutrophil } \\
\text { (cell/ } \mu \mathrm{l})\end{array}$} & \multirow{2}{*}{$\begin{array}{l}\text { Lymphocyte } \\
\text { (cell/ } \mu \mathrm{l})\end{array}$} & \multirow{2}{*}{ NLR } & \multirow{2}{*}{$\begin{array}{c}\text { Serum CA19-9 } \\
(\mathrm{U} / \mathrm{ml})\end{array}$} \\
\hline & Total & Male & Female & & & & & & \\
\hline $\mathrm{HE}$ & 100 & 37 & 63 & $\begin{array}{l}51 \pm 12 \\
(23-79)\end{array}$ & $\begin{array}{c}6,367 \pm 1,318^{a} \\
(4,300-11,200)\end{array}$ & $\begin{array}{l}3,535 \pm 952^{\mathrm{a}} \\
(286-6,494)\end{array}$ & $\begin{array}{c}2,078 \pm 517 \\
(1,114-3,920)\end{array}$ & $\begin{array}{l}1.77 \pm 0.53^{a} \\
(0.15-3.06)\end{array}$ & $\begin{array}{c}17 \pm 16^{b} \\
(0-75)\end{array}$ \\
\hline BHD & 67 & 36 & 31 & $\begin{array}{l}57 \pm 12 \\
(18-76)\end{array}$ & $\begin{array}{l}8,304 \pm 2,783^{\mathrm{a}, \mathrm{c}} \\
(4,700-20,000)\end{array}$ & $\begin{array}{l}4,975 \pm 2,413^{a, c} \\
(2,044-15,800)\end{array}$ & $\begin{array}{c}2,319 \pm 1,313 \\
(949-4,408)\end{array}$ & $\begin{array}{l}2.65 \pm 2.16^{\mathrm{a}, \mathrm{c}} \\
(0.67-9.55)\end{array}$ & $\begin{array}{c}152 \pm 310^{\mathrm{b}, \mathrm{c}} \\
(0-1000)\end{array}$ \\
\hline OCA & 50 & 28 & 20 & $\begin{array}{l}56 \pm 11 \\
(18-76)\end{array}$ & $\begin{array}{l}7,515 \pm 2,385^{\mathrm{a,d}} \\
(2,610-13,500)\end{array}$ & $\begin{array}{l}4,569 \pm 2,133^{a, d} \\
(1,240-10,948)\end{array}$ & $\begin{array}{l}2,005 \pm 693 \\
(680-3,410)\end{array}$ & $\begin{array}{l}2.67 \pm 2.14^{\mathrm{a}, \mathrm{c}} \\
(0.91-13.59)\end{array}$ & $\begin{array}{l}45 \pm 83^{c} \\
(0-427)\end{array}$ \\
\hline CCA & 103 & 73 & 30 & $\begin{array}{l}55 \pm 10 \\
(34-84)\end{array}$ & $\begin{array}{l}12,352 \pm 4,795^{c} \\
(4,100-28,100)\end{array}$ & $\begin{array}{l}8,795 \pm 4,412^{c} \\
(2,214-23,885)\end{array}$ & $\begin{array}{c}2,254 \pm 1,020 \\
(460-5,462)\end{array}$ & $\begin{array}{l}4.91 \pm 3.95^{c} \\
(0.87-23.25)\end{array}$ & $\begin{array}{c}22,753 \pm 104,656^{\mathrm{d}} \\
(0-726,400)\end{array}$ \\
\hline
\end{tabular}

Data are mean $\pm \mathrm{SD}$, numbers in the parentheses are min-max.

$\mathrm{a}=\mathrm{P}<0.001 ; \mathrm{b}=\mathrm{P}<0.01$ vs. CCA group; $\mathrm{c}=\mathrm{P}<0.001, \mathrm{~d}=\mathrm{P}<0.05$ vs. HE groups.

$\mathrm{HE}=$ Healthy persons, $\mathrm{BHD}=$ Benign hepato-biliary diseases, $\mathrm{OCA}=$ other cancers

NLR is Increased in CCA Patients and can Potentially be Used for Primary Diagnosis of CCA.

The ratio between the absolute numbers of peripheral blood neutrophils to lymphocytes was calculated as "NLR". The normal subjects in this study had a mean NLR value of $1.77 \pm 0.53$ which was comparable to that of another study [9]. The CCA group exhibited NLR values ranging from 0.87-23.25. Given an NLR of 1.69 as normal [9], 89.3\% (92/103) of CCA patients had abnormal NLRs, whereas 70.1\% (47/67) of BHD and $66 \%$ (33/50) of OCA possessed abnormal NLRs. The average NLR of the CCA group was significantly higher than those of all non-CCA groups ( $\mathrm{P}<0.001$; Table 1$)$. The
NLRs of BHD and OCA groups were only slightly higher but still statistically different from the HE controls $(\mathrm{P}<0.001$; Figure $2 \mathrm{~A} \&$ Table 1). To assess the power of NLR in discriminating CCA from the control groups, ROC was analyzed. NLR significantly differentiated CCA patients from non-CCA controls $(\mathrm{P}<0.001)$ with an area under curve of 0.773 (Figure 2B). The diagnostic values were calculated based on the cut-off value of NLR $>2.38$ as suggested by the ROC curve. The NLR > 2.38 provided $70.9 \%$ (74/103) sensitivity, $69.1 \%$ (150/217) specificity, $52.1 \%$ (73/140) positive predictive value, $83.3 \%$ (150/180) negative predictive value, 30.9\% (67/217) false positive, 29.1\% (29/103) false negative, and 69.7\% (223/320) accuracy (Table 2).

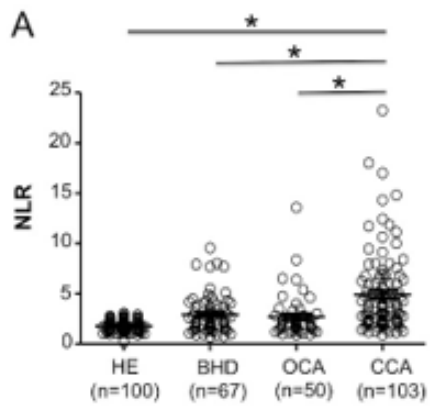

B

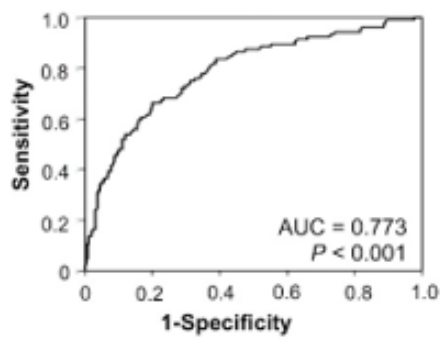

C

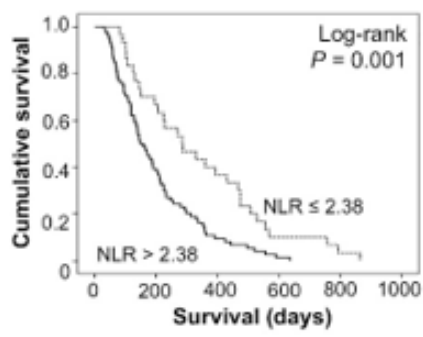

Figure 2: NLR as a diagnostic and prognostic marker of CCA.

A. NLR of CCA patients were significantly higher than those of $\mathrm{HE}, \mathrm{BHD}$, and OCA $\left({ }^{*} \mathrm{P}<0.001\right.$, student t-test).

B. ROC analysis indicated that NLR could discriminate CCA from non-CCA (AUC $=0.773, \mathrm{P}<0.001$ ).

C. Kaplan Meier plot and log rank test revealed that high NLR (NLR > 2.38) significantly indicated shorter survival of CCA patients $(\mathrm{P}<0.001)$.

Cite this article: Chalermwat C, Silsirivanit A, Saentaweesuk S, Bhudisawasdi V, Wongkham S, et al. Neutrophil-to-Lymphocyte Ratio: A Systemic Inflammatory Index for Primary Diagnosis and Prognosis of Cholangiocarcinoma. Biomed J Sci \& Tech Res 13(2)-2019. BJSTR. MS.ID.002375. DOI: 10.26717/ BJSTR.2019.13.002375. 
Table 2: Diagnostic values of NLR and serum CA19-9 for CCA.

\begin{tabular}{|c|c|c|c|c|c|c|c|c|}
\hline \multirow{2}{*}{ Diagnostic values } & \multicolumn{2}{|c|}{ CCA vs. non-CCA } & \multicolumn{2}{c|}{ CCA vs. HE } & \multicolumn{2}{c|}{ CCA vs. BHD } & \multicolumn{2}{c|}{ CCA vs. OCA } \\
\hline & NLR & CA19-9 & NLR & CA19-9 & NLR & CA19-9 & NLR & CA19-9 \\
\hline Sensitivity (\%) & 70.9 & 67.0 & 70.9 & 67.0 & 70.9 & 67.0 & 70.9 & 67.0 \\
\hline Specificity (\%) & 69.1 & 79.3 & 84.0 & 88.0 & 50.7 & 68.7 & 64.0 & 76.0 \\
\hline Positive predictive value (\%) & 52.1 & 60.5 & 82.2 & 85.2 & 69.1 & 76.7 & 80.4 & 85.2 \\
\hline Negative predictive value (\%) & 83.3 & 83.5 & 74.3 & 72.1 & 54.0 & 57.5 & 52.5 & 76.0 \\
\hline False positive (\%) & 30.9 & 20.7 & 16.0 & 12.0 & 49.3 & 31.3 & 36.0 & 24.0 \\
\hline False negative (\%) & 29.1 & 33.0 & 29.1 & 33.0 & 29.1 & 33.0 & 29.1 & 33.0 \\
\hline Accuracy (\%) & 69.7 & 75.3 & 77.8 & 77.3 & 63.5 & 67.6 & 69.3 & 69.9 \\
\hline
\end{tabular}

CCA $(n=103)$, non-CCA $(n=217), \operatorname{HE}(n=100), \operatorname{BHD}(n=67)$, OCA $(n=50)$.

\section{Diagnostic Powers of CA19-9 and NLRs for Diagnosis of CCA are Comparable}

Serum CA19-9, a general tumor marker for CCA, of each subject was also determined for comparison with NLR. Serum CA19-9 levels of the disease groups (BHD, OCA and CCA) were significantly higher than those of the healthy control groups (Table 1). The level of CA19-9 of OCA, however, was not significantly different from those of BHD. Given the CA19-9 of $37 \mathrm{U} / \mathrm{ml}$ as the normal level, $12.0 \%(12 / 100)$ of HE, 31.3\% (21/67) of BHD, $24.0 \%(12 / 50)$ of OCA and $67.0 \%(69 / 103)$ of CCA had a CA19-9 higher than the normal value. Of these, the CA19-9 level of the CCA group had highest diversity and was markedly higher than those of OCA, BHD and HE groups $(\mathrm{P}<0.001$; Table $1 \&$ Figure $3 \mathrm{~A})$. To determine the diagnostic powers of CA19-9 in this studied cohort, the ROC analysis was performed. CA19-9 could discriminate CCA from non-CCA (P $<0.001$ ) with an area under curve of 0.763 (Figure 3B). Using a general diagnostic cut off value at $37 \mathrm{U} / \mathrm{ml}$, CA19-9 provided $67.0 \%$ (69/103) sensitivity, 79.3\% (172/217) specificity, 60.5\% (69/114) positive predictive value, $83.5 \%(172 / 206)$ negative predictive value, $20.7 \%$ (45/217) false positive, $33.0 \%$ (34/103) false negative, and $75.3 \%(241 / 320)$ accuracy. Table 2 demonstrates the discriminating powers of NLR and serum CA19-9 for diagnosis of CCA in the different control groups.
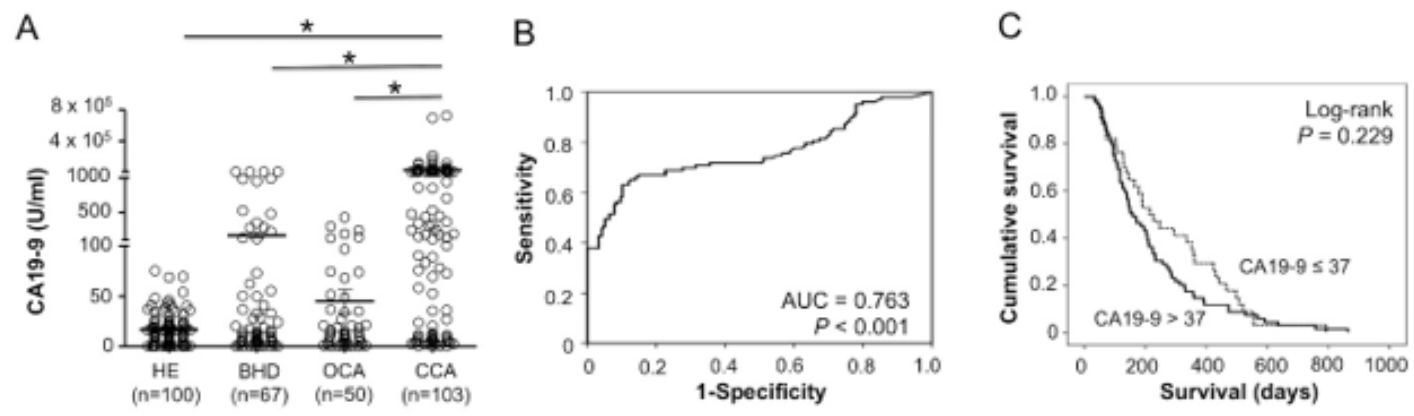

Figure 3: CA19-9 as a diagnostic and prognostic marker of CCA.

A. Level of serum CA19-9 of CCA patents was significantly higher than those of HE, BHD, and OCA ( ${ }^{*} \mathrm{P}<0.001$, student $\mathrm{t}$-test).

B. Using ROC analysis, CA19-9 discriminated CCA from non-CCA with AUC $=0.763(\mathrm{P}<0.001)$.

C. CA19-9, at cut-off $37 \mathrm{U} / \mathrm{ml}$, was not related to survival of CCA patients $(\mathrm{P}=0.229)$.

\section{Higher NLRs Indicate Poor Clinical Outcomes of CCA Patients}

Overall median survival of CCA patients in this study was 186 days with $95 \%$ CI of 136.3-235.7 days. To signify the prognostic relevance of NLR, CCA patients were categorized according to NLR value into 2 groups, low NLR (NLR $\leq 2.38)$ and high NLR (NLR > 2.38). Survival analysis using Kaplan Meier plot and log rank test showed that CCA patients with high NLR (median survival 148 days; 95\% CI, 115.4-180.6 days) exhibited significantly shorter survivals compared to those with low-NLR (median survival 284 days; 95\% CI, 147.1-420.9 days) ( $\mathrm{P}=0.001$; Figure $2 \mathrm{C})$. In addition, the univariate analysis revealed that NLR had a positive correlation with tumor size $(\mathrm{P}=0.042)$ but no other parameters e.g., age, sex, histological types, tumor stages, jaundice, CEA and CA19-9 (Table 3). Multivariate analysis using the Cox-proportional hazard model revealed the clinical significance of NLR as an independent prognostic factor for CCA $(\mathrm{P}=0.004$; Table 4). Compared with NLR, serum CA19-9 at cut-off $37 \mathrm{U} / \mathrm{ml}$ was not related to survival of CCA patients $(\mathrm{P}=0.229$; Figure $3 \mathrm{C})$. 
Table 3: Correlation of NLR and clinical parameters of CCA patients.

\begin{tabular}{|c|c|c|c|c|}
\hline \multicolumn{2}{|c|}{ Clinical parameters } & \multirow{2}{*}{$\begin{array}{c}\mathbf{N L R} \leq \mathbf{2 . 3 8} \\
12\end{array}$} & \multirow{2}{*}{$\begin{array}{c}\text { NLR }>2.38 \\
38\end{array}$} & \multirow{2}{*}{$\begin{array}{c}\mathbf{P} \\
0.266\end{array}$} \\
\hline Age & $\leq 55$ year & & & \\
\hline & $>55$ year & 18 & 35 & \\
\hline \multirow[t]{2}{*}{ Sex } & Male & 17 & 55 & 0.060 \\
\hline & Female & 13 & 18 & \\
\hline \multirow[t]{2}{*}{ Histological type } & PAP & 8 & 12 & 0.233 \\
\hline & Non-PAP & 22 & 61 & \\
\hline \multirow[t]{2}{*}{ Staging } & I-III & 6 & 6 & 0.090 \\
\hline & IV & 24 & 67 & \\
\hline \multirow[t]{2}{*}{ Tumor size } & $\leq 5 \mathrm{~cm}$ & 7 & 7 & 0.042 \\
\hline & $>5 \mathrm{~cm}$ & 7 & 27 & \\
\hline \multirow[t]{2}{*}{ Jaundice } & $\mathrm{TB} \leq 2 \mathrm{mg} / \mathrm{dl}$ & 22 & 40 & 0.081 \\
\hline & $\mathrm{TB}>2 \mathrm{mg} / \mathrm{dl}$ & 8 & 33 & \\
\hline \multirow[t]{2}{*}{ CA19-9 } & $\leq 37 \mathrm{U} / \mathrm{ml}$ & 10 & 24 & 0.964 \\
\hline & $>37 \mathrm{U} / \mathrm{ml}$ & 20 & 49 & \\
\hline \multirow[t]{2}{*}{ CEA } & $\leq 5 \mathrm{ng} / \mathrm{ml}$ & 14 & 37 & 0.711 \\
\hline & $>5 \mathrm{ng} / \mathrm{ml}$ & 16 & 36 & \\
\hline
\end{tabular}

Table 4: Cox-proportional hazard models.

\begin{tabular}{|c|c|c|c|c|}
\hline & $\mathbf{n}$ & Adjusted HR & $95 \% \mathrm{CI}$ & $\mathbf{P}$ \\
\hline \multicolumn{5}{|l|}{ NLR } \\
\hline$\leq 2.38$ & 30 & 1 & $1.203-5.469$ & 0.015 \\
\hline$>2.38$ & 73 & 2.565 & & \\
\hline \multicolumn{5}{|l|}{ Age } \\
\hline$\leq 55$ year & 50 & 1 & $1.397-5.492$ & 0.004 \\
\hline$>55$ year & 53 & 2.770 & & \\
\hline \multicolumn{5}{|l|}{ Sex } \\
\hline Male & 72 & 1 & $0.239-0.963$ & 0.039 \\
\hline Female & 31 & 0.479 & & \\
\hline \multicolumn{5}{|c|}{ Histological type } \\
\hline PAP & 20 & 1 & $1.397-6.499$ & 0.005 \\
\hline Non-PAP & 83 & 3.013 & & \\
\hline \multicolumn{5}{|l|}{ Staging } \\
\hline I-III & 12 & 1 & $0.419-3.948$ & 0.660 \\
\hline IV & 91 & 1.286 & & \\
\hline \multicolumn{5}{|l|}{ Tumor size } \\
\hline$\leq 5 \mathrm{~cm}$ & 14 & 1 & $0.725-4.851$ & 0.195 \\
\hline$>5 \mathrm{~cm}$ & 34 & 1.876 & & \\
\hline
\end{tabular}




\section{Discussion}

Lymphocytes, neutrophils and monocytes are cellular mediated inflammatory responders that play significant roles in tumor development and progression. In the past decade, NLR has been recognized as an independent prognostic factor in many cancers, including CCA [3,10-15]. A recent meta-analysis revealed that a higher pre-operative NLR was associated with the unfavorable prognosis of CCA patients [16]. A series of studies compared liver fluke-related and non-liver fluke-infected CCA, identified distinct expression profiles [17], different somatic mutations [18] and different DNA hypermethylaion patterns [19]. A high NLR has been reported as a poor prognostic marker for non-liver fluke-infected CCA in many studies. This study shows for the first time in liver fluke-related CCA, that NLR can be used as,

a) A diagnostic indicator;

b) Prognostic indicator; and

c) An equivalent marker with CA19-9 for primary screening for CCA.

CCA is difficult to diagnose at an early stage, which may be due to the non-specific symptoms and lacking an early and sensitive marker. As a consequence, most of CCA patients are detected at a late stage when the tumor has metastasized. There are many attempts searching for serum biomarkers that can differentiate CCA with a high sensitivity and specificity, e.g., mucin-MUC5AC [20], interleukin-6 [21], and CA-S121 [22]. Although these markers provided a satisfactory diagnostic power for CCA, the use of these biomarkers in clinical practice is limited. This may due to the assays of these markers are unavailable in the routine service of the hospitals. On the other hand, serum CA19-9 and CEA, even with lower sensitivity and specificity, are however, the common markers used for diagnosis of CCA. This may be because they are available in the hospital laboratory. A complete blood count is basic blood analysis used to support clinical investigations in every hospital. In the present study, NLR and serum CA19-9 were determined in parallel. In this setting, NLR was shown to be a potential diagnostic marker for CCA with $70.9 \%$ sensitivity and $69.1 \%$ specificity comparable with those of serum CA19-9 with $67.0 \%$ sensitivity and $79.3 \%$ specificity.

CCA patients possessed high numbers of WBCs and neutrophils that may generate a high NLR compared with the control groups. ROC suggested NLR $>2.38$ as the cut-off that could differentiate CCA patients from the control groups. In addition, both NLR and serum CA19-9 could be used to distinguish HE, BHD and OCA from CCA with similar diagnostic powers (Table 2). The results presented herein, suggest that NLR had a diagnostic power for differentiating CCA equivalent to serum CA19-9. NLR was recently reported to be a candidate for primary diagnosis in many types of cancers such as gastric cancer [23], glioma [24], and pancreatic cancer [25]. In these previous studies, NLR yielded diagnostic powers for sensitivity of 47.3-78.3\% and specificity of 76.0-90.5\% for diagnosis of the diseases. When compared with the present study, NLR showed a nearly $70 \%$ sensitivity and specificity for diagnosis of CCA. In combination with other markers, NLR, could increase the diagnostic efficiency of the single test. For example, in gastric cancer, compared with CEA alone, a combined NLR with CEA increased the specificity of diagnosis from $78.77 \%$ to $89.44 \%$ but reduced sensitivity from $54.23 \%$ to $51.24 \%$ [23]. Based on current analysis, a combined NLR and CA19-9 raised up the specificity for non-CCA exclusion of CA19-9 from $79.3 \%$ to $88.5 \%$ (data not shown). The sensitivity of CA19-9 to detect CCA, however, was reduced from $67.0 \%$ to $47.6 \%$, suggesting a combined NLR and CA19-9 approach may be of benefit to screen out non-CCA persons.

Many studies in the past decade indicated NLR as an independent prognostic factor for many solid tumors including CCA $[5,10,26]$. Recently, a systematic review and meta-analysis of NLR as a prognostic indicator of solid tumors revealed that NLR $>4$ was associated with a hazard ratio for overall survival of 1.81. In the present study, NLR $>2.38$ was significantly associated with unfavorable prognosis of CCA patients with a hazard ratio for overall survival of 2.565. CCA patients with high NLRs $(>2.38)$ had significantly shorter survival than those with a low NLR. Various cut-off NLRs ranging from 2.49 to 5.0 were found to be a poor prognostic indicator of CCA [3,10-15]. A current meta-analysis for NLR as a prognostic indicator for CCA revealed that a higher pre-operative NLR of 2.49-5.0 was associated with an unfavorable prognosis of CCA patients [16]. As all previous studies were reported from non-liver fluke-related CCA, the present study supports that a high NLR can be the prognostic marker for CCA regardless of the causative origins. NLR represents a systemic inflammation and has been marked as an enhancer of tumor progression via promoting angiogenesis and metastasis [27]. Meta-analysis in liver cancers revealed that infiltration of tumor stroma with neutrophils is associated with poor prognosis [5].

The present study demonstrated the association of NLR with tumor size, suggesting the roles of inflammation in promoting tumor growth. This observation was in agreement with the report from Chen and co-workers [10] on the fact that cytokines produced either from inflammatory cells or cancer cells are possibly the factors potentiating cancer cell proliferation and tumor angiogenesis. Previous reports in CCA suggested the elevation of inflammatory cytokines, such as interleukin (IL)-6, IL-8, and TGFbeta, etc., involved in tumor progression and metastasis [28]. A blood smear provides basic information about patient including immune responses via a differential count of white blood cells. NLR, the ratio between neutrophils and lymphocytes, has been shown to be a useful index representing a systemic inflammatory response. In Thailand, the cost for analyzing a CBC is 9 times cheaper than CA19-9, though the diagnostic values for CCA provided by NLR are comparable with CA19-9.

This study suggests NLR as a potential primary diagnostic index for CCA and should be determined before other high cost analysis, e.g., tumor markers, ultrasonography, MRI, or CT-scan are invested in, especially in remote or peripheral hospitals. Taken together, NLR is suggested to be an alternative index considered for primary diagnosis comparable to serum CA19-9. A combined NLR with serum CA19-9 increases the specificity for detection of CCA. As 
$88 \%$ of CCA patients recruited in the present study were patients with metastasis and suspected to be liver fluke-related CCA, the implication of NLR for primary diagnosis of early stage CCA should be interpreted with caution. A high NLR was also demonstrated to be associated with adverse overall survival of patients and could be used as a poor prognostic prediction of CCA regardless of the etiology. This indicator may provide constructive information for therapeutic decision making for individual patients and classify patients in clinical trials. It is then proposed that NLR might be a readily available and an inexpensive marker for primary diagnosis and prognosis of CCA.

\section{Conclusion}

Late diagnosis is a major problem for CCA since the prognosis of a good clinical outcome at advanced stage of the disease is greatly diminished. CCA currently lacks a quick, inexpensive and sensitive marker to reflect the existing of disease. In this study, the potential of NLR as a primary diagnostic and prognostic marker for CCA was demonstrated. Diagnostic values of NLR were comparable with CA19-9, a tumor marker that has been generally used for CCA diagnosis. Moreover, high levels of NLR can predict the poor clinical outcomes of CCA patients. NLR may be a sensitive and inexpensive potential marker for primary diagnosis and prognostic prediction of CCA.

\section{Acknowledgement}

We would like to thank the support from Faculty of Medicine, Khon Kaen University (RG60201), and Prof. James A. Will for English editing via Publication Clinic, KKU. We appreciated the contribution of Ms N. Sridadom, Ms P. Main and the staffs of Department of Clinical Pathology, Srinagarind Hospital for data collection.

\section{References}

1. Sacdalan DB, Lucero JA, Sacdalan DL (2018) Prognostic utility of baseline neutrophil-to-lymphocyte ratio in patients receiving immune checkpoint inhibitors: a review and meta-analysis. Onco Targets Ther 11: 955-965.

2. Tan TP, Arekapudi A, Metha J, Prasad A, Venkatraghavan L (2015) Neutrophil-lymphocyte ratio as predictor of mortality and morbidity in cardiovascular surgery: a systematic review. ANZ J Surg 85: 414-419.

3. He C, Mao Y, Lao X, Li S, Lin X (2018) Neutrophil-to-lymphocyte ratio predicts overall survival of patients with combined hepatocellular cholangiocarcinoma. Oncol Lett 15: 4262-4268.

4. Song JY, Chen MQ, Guo JH, Lian SF, Xu BH (2018) Combined pretreatment serum CA19-9 and neutrophil-to-lymphocyte ratio as a potential prognostic factor in metastatic pancreatic cancer patients. Medicine (Baltimore) 97: e9707.

5. Xue TC, Zhang L, Xie XY, Ge NL, Li LX, et al. (2014) Prognostic significance of the neutrophil-to-lymphocyte ratio in primary liver cancer: a metaanalysis. PLoS One 9: e96072.

6. Blechacz B, Komuta M, Roskams T, Gores GJ (2011) Clinical diagnosis and staging of cholangiocarcinoma. Nat Rev Gastroenterol Hepatol 8: 512-522.

7. Shin HR, Oh JK, Masuyer E, Curado MP, Bouvard V, etal. (2010) Comparison of incidence of intrahepatic and extrahepatic cholangiocarcinoma--focus on East and South-Eastern Asia. Asian Pac J Cancer Prev 11: 1159-1166.

8. Edge SB, Compton CC (2010) The American Joint Committee on Cancer: the 7th edition of the AJCC cancer staging manual and the future of TNM. Ann Surg Oncol 17: 1471-1474.

9. Forget P, Khalifa C, Defour JP, Latinne D, Van Pel MC, et al. (2017) What is the normal value of the neutrophil-to-lymphocyte ratio? BMC Res Notes 10: 12 .

10. Chen Q Yang LX, Li XD, Yin D, Shi SM, et al. (2015) The elevated preoperative neutrophil-to-lymphocyte ratio predicts poor prognosis in intrahepatic cholangiocarcinoma patients undergoing hepatectomy. Tumour Biol 36: 5283-5289.

11. Cho H, Yoo C, Kim KP, Jeong JH, Kang J, et al. (2018) Prognostic Implication of Inflammation-based Prognostic Scores in Patients with Intrahepatic Cholangiocarcinoma Treated with First-line Gemcitabine plus Cisplatin. Invest New Drugs 36(3): 496-502.

12. Gomez D, Morris-Stiff G, Toogood GJ, Lodge JP, Prasad KR (2008) Impact of systemic inflammation on outcome following resection for intrahepatic cholangiocarcinoma. J Surg Oncol 97: 513-518.

13. Hamed MO, Roberts KJ, Smith AM, Morris Stiff G (2013) Elevated pre-operative neutrophil to lymphocyte ratio predicts disease free survival following pancreatic resection for periampullary carcinomas. Pancreatology 13: 534-538.

14. Lee BS, Lee SH, Son JH, Jang DK, Chung KH, et al. (2016) Neutrophillymphocyte ratio predicts survival in patients with advanced cholangiocarcinoma on chemotherapy. Cancer Immunol Immunother 65: 141-150.

15. McNamara MG, Templeton AJ, Maganti M, Walter T, Horgan AM, et al. (2014) Neutrophil/lymphocyte ratio as a prognostic factor in biliary tract cancer. Eur J Cancer 50: 1581-1589.

16. Tan DW, Fu Y, Su Q Guan MJ, Kong P, et al. (2016) Prognostic Significance of Neutrophil to Lymphocyte Ratio in Oncologic Outcomes of Cholangiocarcinoma: A Meta-analysis. Sci Rep 6: 33789.

17. Jinawath N, Chamgramol Y, Furukawa Y, Obama K, Tsunoda T, et al. (2006) Comparison of gene expression profiles between Opisthorchis viverrini and non-Opisthorchis viverrini associated human intrahepatic cholangiocarcinoma. Hepatology 44: 1025-1038.

18. Ong CK, Subimerb C, Pairojkul C, Wongkham S, Cutcutache I, et al. (2012) Exome sequencing of liver fluke-associated cholangiocarcinoma. Nat Genet 44: 690-693.

19. Jusakul A, Cutcutache I, Yong CH, Lim JQ, Huang MN, et al. (2017) WholeGenome and Epigenomic Landscapes of Etiologically Distinct Subtypes of Cholangiocarcinoma. Cancer Discov 7: 1116-1135.

20. Bamrungphon W, Prempracha N, Bunchu N, Rangdaeng S, Sandhu T, et al. (2007) A new mucin antibody/enzyme-linked lectin-sandwich assay of serum MUC5AC mucin for the diagnosis of cholangiocarcinoma. Cancer Lett 247: 301-308.

21. Sripa B, Pairojkul C (2008) Cholangiocarcinoma: lessons from Thailand. Curr Opin Gastroenterol 24: 349-356.

22. Silsirivanit A, Araki N, Wongkham C, Pairojkul C, Narimatsu Y, et al. (2011) A novel serum carbohydrate marker on mucin 5AC: values for diagnostic and prognostic indicators for cholangiocarcinoma. Cancer 117: 3393-3403.

23. Wu Y, Jiang M, Qin Y, Lin F, Lai M (2018) Single and combined use of neutrophil-lymphocyte ratio, platelet-lymphocyte ratio and carcinoembryonic antigen in diagnosing gastric cancer. Clin Chim Acta 481: $20-24$.

24.Zheng SH, Huang JL, Chen M, Wang BL, Ou QS, et al. (2017) Diagnostic value of preoperative inflammatory markers in patients with glioma: a multicenter cohort study. J Neurosurg 1-10.

25. Liu JX, Li A, Zhou LY, Liu XF, Wei ZH, et al. (2018) Significance of combined preoperative serum Alb and dNLR for diagnosis of pancreatic cancer. Future Oncol 14: 229-239.

Cite this article: Chalermwat C, Silsirivanit A, Saentaweesuk S, Bhudisawasdi V, Wongkham S, et al. Neutrophil-to-Lymphocyte Ratio: A Systemic Inflammatory Index for Primary Diagnosis and Prognosis of Cholangiocarcinoma. Biomed J Sci \& Tech Res 13(2)-2019. BJSTR. MS.ID.002375. DOI: 10.26717 / BJSTR.2019.13.002375. 
26. Grenader T, Waddell T, Peckitt C, Oates J, Starling N, et al. (2016) Prognostic value of neutrophil-to-lymphocyte ratio in advanced oesophago-gastric cancer: exploratory analysis of the REAL-2 trial. Ann Oncol 27: 687-692.

27. Coussens LM, Werb Z (2002) Inflammation and cancer. Nature 420: 860867.

\section{ISSN: 2574-1241}

DOI: 10.26717/BJSTR.2019.13.002375

Sopit Wongkham. Biomed J Sci \& Tech Res

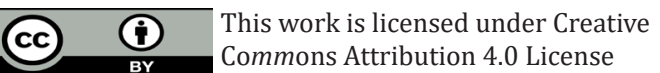

Submission Link: https://biomedres.us/submit-manuscript.php
28. Landskron G, De la Fuente M, Thuwajit P, Thuwajit C, Hermoso MA (2014) Chronic inflammation and cytokines in the tumor microenvironment. J Immunol Res 2014: 149185.

$\begin{array}{ll}\text { BIOMEDICAL } & \text { Assets of Publishing with us } \\ \text { RESEARCHES } & \text { - Global archiving of articles } \\ \text { - Immediate, unrestricted online access }\end{array}$

